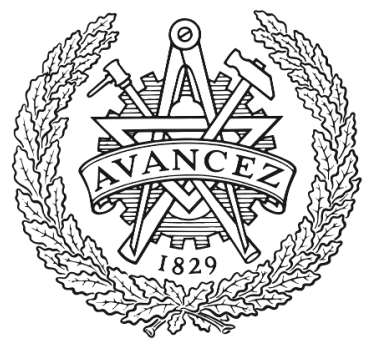

CHALMERS

UNIVERSITY OF TECHNOLOGY

\title{
Palladium Catalyzed Stereoselective Arylation of Biocatalytically Derived Cyclic 1,3-Dienes: Chirality Transfer via a Heck-Type Mechanism
}

Downloaded from: https://research.chalmers.se, 2023-04-26 12:45 UTC

Citation for the original published paper (version of record):

Paterson, A., Dunås, P., Rahm, M. et al (2020). Palladium Catalyzed Stereoselective Arylation of Biocatalytically Derived Cyclic 1,3-Dienes:

Chirality Transfer via a Heck-Type Mechanism. Organic Letters, 22(6): 2464-2469.

http://dx.doi.org/10.1021/acs.orglett.0c00708

N.B. When citing this work, cite the original published paper. 


\title{
Palladium Catalyzed Stereoselective Arylation of Biocatalytically Derived Cyclic 1,3-Dienes: Chirality Transfer via a Heck-Type Mechanism
}

\author{
Andrew J. Paterson, ${ }^{\ddagger}$ Petter Dunås, ${ }^{\ddagger}$ Martin Rahm,* Per-Ola Norrby, Gabriele Kociok-Köhn, \\ Simon E. Lewis,* and Nina Kann*
}

Cite This: Org. Lett. 2020, 22, 2464-2469

Read Online

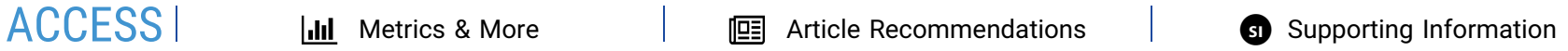

ABSTRACT: Microbial arene oxidation of benzoic acid with Ralstonia eutropha B9 provides a chiral highly functionalized cyclohexadiene, suitable for further structural diversification. Subjecting this scaffold to a Pd-catalyzed Heck reaction effects a regio- and stereoselective arylation of the cyclohexadiene ring, with 1,3-chirality transfer of stereogenic information installed in the microbial arene oxidation. Quantum chemical calculations explain

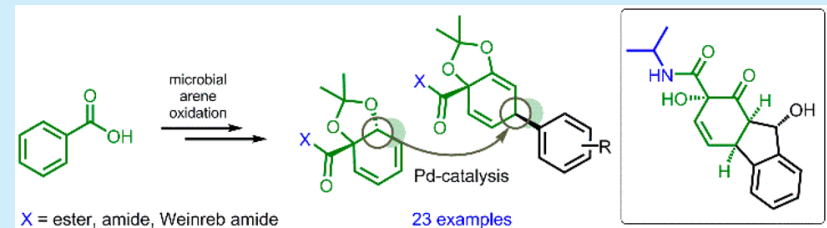
the selectivity both by a kinetic preference for the observed arylation position and by reversible carbopalladation in competing positions. Further product transformation allowed the formation of a tricyclic ketone possessing four stereogenic centers. This demonstrates the capability of the method to introduce stereochemical complexity from planar nonchiral benzoic acid in just a few steps.

$\mathrm{T}^{\mathrm{s}}$ he biocatalytic transformation of arenes into dearomatized cis-dihydroxylated species can be achieved using arene dioxygenase enzymes via microbial arene oxidation (MAO). ${ }^{1}$ While complete oxidation affords a catechol, the use of mutant strains ${ }^{2}$ or recombinant organisms ${ }^{3}$ allows isolation of the intermediate chiral diol, enabling conversion of a flat arene into a chiral functionalized scaffold, suitable for further transformations. Many dioxygenase enzymes are known and generally lead to ortho/meta dihydroxylation with respect to pre-existing functionality. ${ }^{4}$ However, benzoate dioxygenase (BZDO), expressed by $R$. eutropha $\mathrm{B} 9,{ }^{5}$ transforms benzoic acid with complementary selectivity, affording ipso/ortho dihydroxylated product $\mathbf{1}$ as a single enantiomer (Scheme 1a). Compound $\mathbf{1}$ has been subjected to various transformations such as oxidations and acetalization ${ }^{6}$ and been used for preparing natural products ${ }^{7}$ and pharmaceuticals. ${ }^{8}$ One diversification approach could involve metal-catalyzed crosscoupling of the diene $\mathrm{sp}^{2}$-carbons. 9 The Mizoroki-Heck reaction ${ }^{10}$ allows arylation of an alkene under Pd-catalysis and can potentially lead to chirality transfer from one ring carbon to another. Such chirality transfer has been demonstrated in the synthesis of $C$-glycosides, ${ }^{11}$ where the coupling effects a double bond migration and 1,3-chirality transfer (Scheme 1b). However, achieving selectivity with a diene such as $\mathbf{1}$ could be challenging. Studies of Pd-catalyzed reactions involving substrates obtained via $\mathrm{MAO}$ are limited, ${ }^{6 c, 12}$ and to the best of our knowledge, Heck arylation of $\mathbf{1}$ and its derivatives has not been described. Furthermore, this type of chirality transfer in intermolecular Heck reactions has not been investigated to any great extent outside of glycal arylations. We herein report
Scheme 1. Arylation of Microbial Arene Oxidation Products (a) Microbial arene oxidation

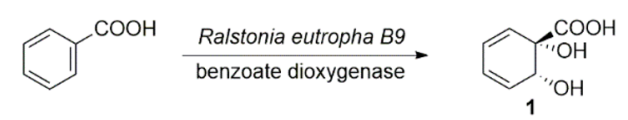

(b) Heck arylation with 1,3-chirality transfer in C-glycoside synthesis (previous work)
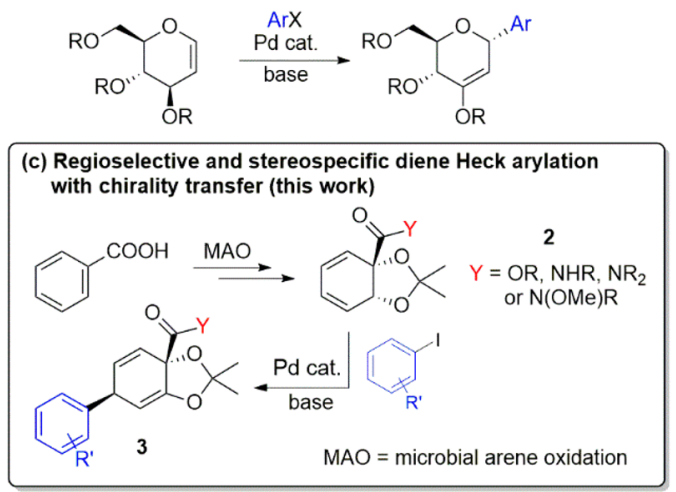

Received: February 24, 2020

Published: March 9, 2020 
our findings concerning the conversion of esters and amides 2, obtained from 1, into chiral arylated 1,4-dienes such as 3 (Scheme 1c). A quantum chemical study was also conducted to elucidate the origin of the high selectivity.

Results and Discussion. Ester 2a (Table 1), with an acetal protected cis-diol, was chosen as a suitable substrate and was

Table 1. Optimization of the Pd-Catalyzed Arylation of 2a with Iodobenzene ${ }^{a}$

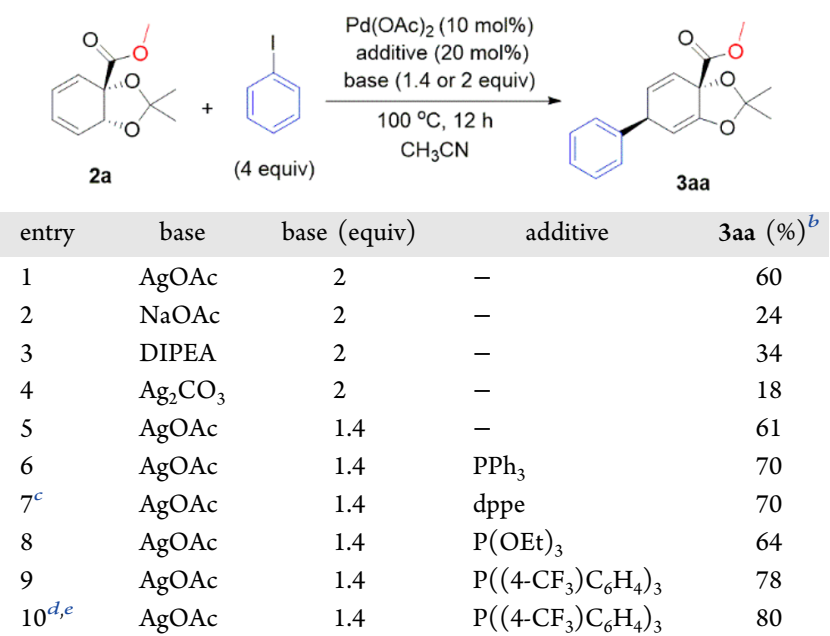

${ }^{a}$ Performed under reflux conditions in a Carousel 12 Plus Reaction Station from Radleys, using a metal heating block. ${ }^{b} \mathrm{NMR}$ yield. ${ }^{c} 10$ mol \% dppe. ${ }^{d} 5 \mathrm{~mol} \% \mathrm{Pd}(\mathrm{OAc})_{2} .{ }^{e} 10 \mathrm{~mol} \% \mathrm{P}\left(\left(4-\mathrm{CF}_{3}\right) \mathrm{C}_{6} \mathrm{H}_{4}\right)_{3}$.

subjected to Pd-catalyzed arylation with iodobenzene. With a diene such as $\mathbf{2 a}$, several products can potentially be formed under these conditions. However, we were gratified to see that using iodobenzene, $\mathrm{Pd}(\mathrm{OAc})_{2}$, and $\mathrm{AgOAc}$ in acetonitrile resulted in the completely regio- and diasteroselective arylation of $2 \mathrm{a}$ to form diene $3 \mathrm{aa}$ in $60 \%$ yield (Table 1 , entry 1 ). Through this reaction, stereochemical information initially present in the diol moiety is transferred to a more distal position.

Other bases and silver sources are less effective (entries 24), but the amount of silver salt could be reduced to 1.4 equiv, maintaining the same reactivity (entry 5). However, a palladium loading of $10 \%$ and 4 equiv of the aryl iodide were necessary for full conversion and a high degree of product formation. A range of phosphine ligands were subsequently screened (entries 6-9), and $\mathrm{P}\left(\left(4-\mathrm{CF}_{3}\right) \mathrm{C}_{6} \mathrm{H}_{4}\right)_{3}$ (entry 9) was identified as most effective. After reassessing the reaction conditions, the use of $\mathrm{P}\left(\left(4-\mathrm{CF}_{3}\right) \mathrm{C}_{6} \mathrm{H}_{4}\right)_{3}$ allows the palladium and ligand loading to be reduced to $5 \%$ and $10 \%$, respectively, while maintaining comparable reactivity (entry 10; see Supporting Information (SI) for full optimization).

With the optimized conditions in hand, we investigated the scope of arylation reagents using ester $\mathbf{2 a}$ (Scheme 2). Aryl iodides with electron-rich or -neutral substituents at the para position perform comparably well, providing the arylated products in good yields (compounds 3aa-3ad). Electrondeficient arenes afford products in somewhat lower yields (3ae-3af). Notably, 1-bromo-4-iodobenzene reacts selectively at the $\mathrm{Ar}-\mathrm{I}$ bond, producing $66 \%$ of $3 \mathrm{ae}$. Different substitution patterns on the aryl ring are also tolerated with 2- or 3substituted aryl iodides (3af-3am). In terms of limitations, certain functional groups are not tolerated on the aryl iodide, including aldehyde, phenol, and amine. Whereas indole can be
Scheme 2. Scope and Limitations of Aryl Halides in the Reaction with $2 a^{a}$
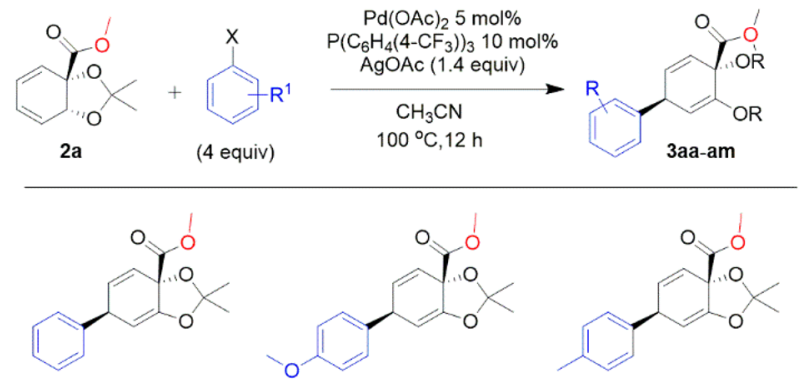

3aa $77 \%(74 \%) \quad$ 3ab $81 \%(79 \%) \quad$ 3ac $76 \%(76 \%)$
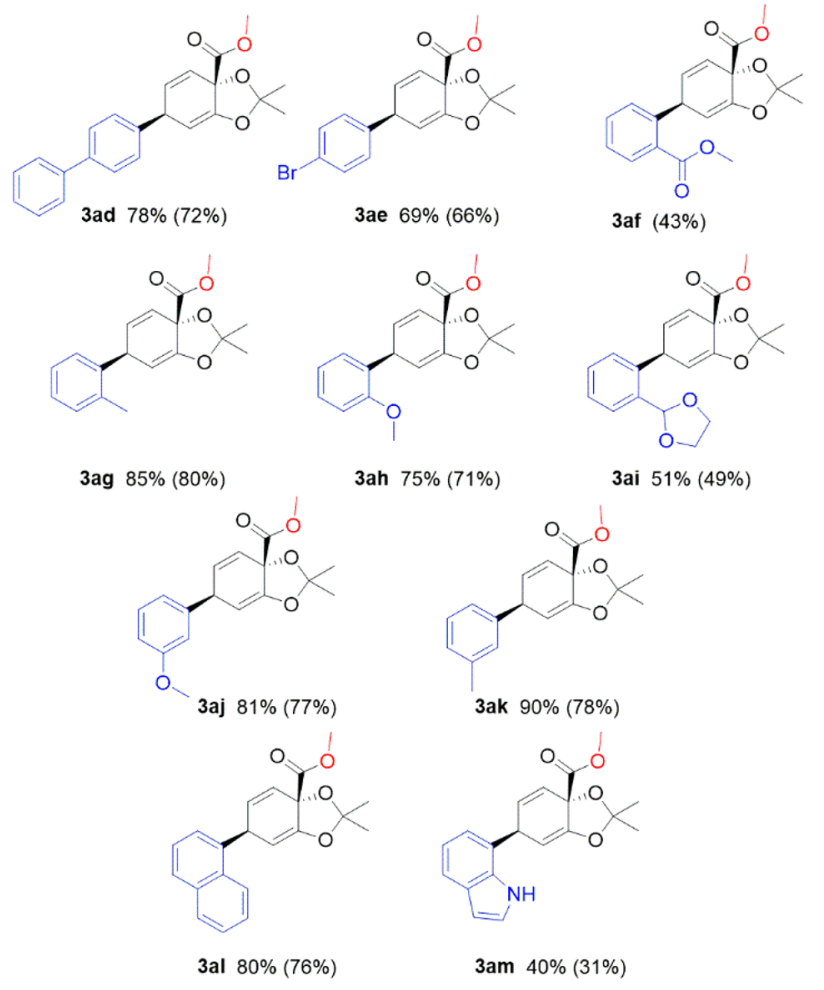

Unsuccessful aryl halides:
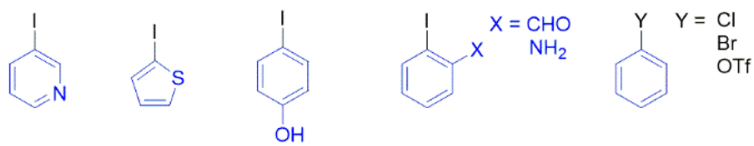

${ }^{a}$ Performed in a Carousel 12 Plus Reaction Station from Radleys, using a metal heating block. NMR yields (isolated yields in parentheses). Products formed with complete diastereoselectivity.

coupled to the 7-position (3am), other heterocyclic aryl iodides are unsuccessful. Likewise, other aryl halides or pseudohalides do not react under these conditions. A crystal structure of compound 3ah (Figure 1) verifies this structure unequivocally.

We next investigated the scope of the starting diene. In addition to ester $\mathbf{2 a}$, amides and secondary esters perform well, affording $\mathbf{3 b a}-\mathbf{3} \mathbf{d b}$ in good yields (Scheme 3 ). Furthermore, a Weinreb amide, as in $\mathbf{3 e b}$, could be applied and is potentially useful for postfunctionalization. Substrates 1 and 4-6 were also tested but did not afford arylated products. 


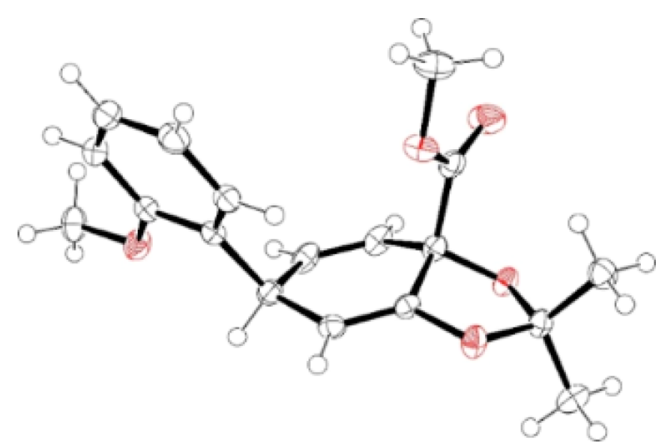

Figure 1. Solid state structure of compound 3ah. Ellipsoids are represented at $50 \%$ probability. $\mathrm{H}$ atoms are shown as spheres of arbitrary radius. CCDC 1961899.

\section{Scheme 3. Substrate Scope and Limitations ${ }^{a}$}
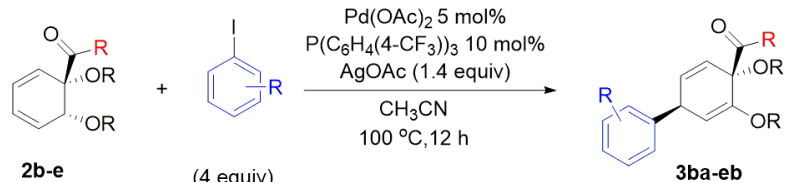

2b-e (4 equiv)

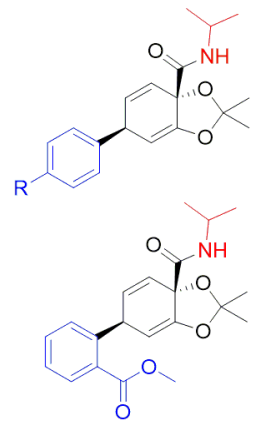

3bf $50 \%(46 \%)$

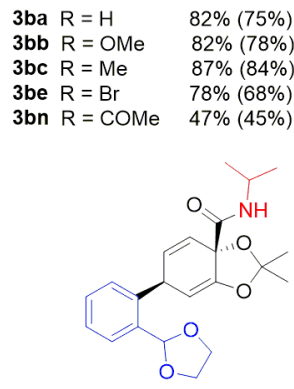

3bi $58 \%(47 \%)$

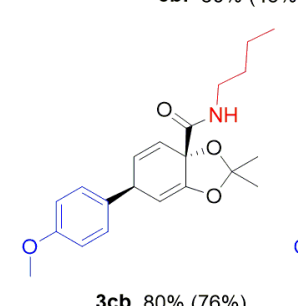

3cb $80 \%(76 \%)$

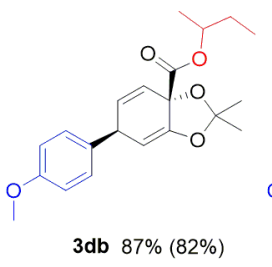

$3 \mathrm{db} 87 \%(82 \%)$

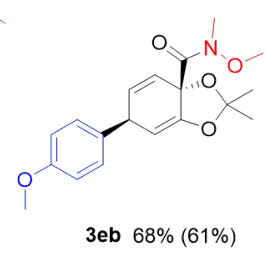

3eb $68 \%(61 \%)$

$$
\text { Unsuccessful substrates: }
$$
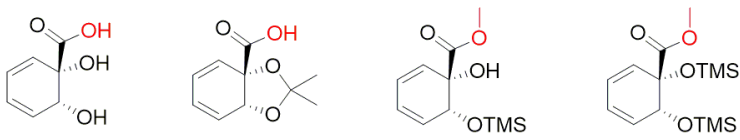

${ }^{a}$ Performed in a Carousel 12 Plus Reaction Station from Radleys, using a metal heating block. NMR yields (isolated yields in parentheses). Products formed with complete diastereoselectivity, with the exception of $\mathbf{3 d b}$, formed as a 1:1 mixture of diastereomers.

We subsequently explored further synthetic transformations of products 3. Cleavage of the acetal in $3 \mathbf{b a}$ and $3 \mathbf{b f}$, using $\mathrm{CF}_{3} \mathrm{COOH}$, afforded ketones $7 \mathbf{b a}$ and $7 \mathbf{b f}$ in high yields (Scheme 4 , route A). Compound $7 \mathbf{b f}$, containing a ketone and a proximal ester group, could potentially undergo an
Scheme 4. Further Transformations of $3 b a, 3 b f$, and $3 b i$
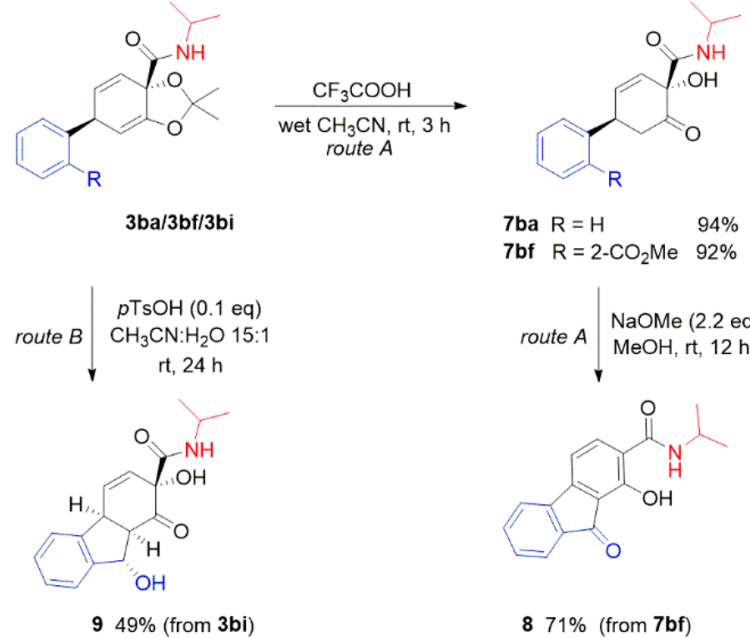

7 bf $\mathrm{R}=2-\mathrm{CO}_{2} \mathrm{Me} \quad 92 \%$
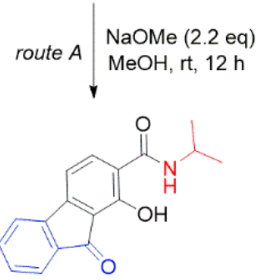

$871 \%$ (from $7 \mathbf{b f}$ )

intramolecular Claisen condensation, and this feature was investigated. Treating $\mathbf{7 b f}$ with $\mathrm{NaOMe}$ in methanol led to the formation of aromatized fluorenone 8 in $71 \%$ yield, following elimination of $\mathrm{H}_{2} \mathrm{O}$. While this demonstrates the applicability of these products as enolates, valuable stereochemical information is lost here. To explore other possibilities, we subjected $3 \mathbf{b i}$, with two acetal functionalities, to acidic conditions, envisaging that both groups could be deprotected in one step (Scheme 4, route B). A subsequent acid catalyzed aldol reaction could then result in a cyclized product. We were delighted to see that the use of $p-\mathrm{TsOH}$ in wet acetonitrile led to the formation of tricyclic compound 9. Remarkably, this product, which contains four stereogenic centers, forms with complete diastereoselectivity. This reaction demonstrates that our method can be utilized to build up significant molecular complexity from a flat achiral starting material, benzoic acid.

In order to explain the high regioselectivity and facial selectivity of the transformation, we have performed a quantum chemical study, relying on Density Functional Theory (DFT) calculations. Our calculations, which were done with Gaussian $16,{ }^{13}$ were mostly performed at the B3LYPD3/def2-TZVP//def2-SVPD level of theory. The Solvent Model Density (SMD) method was used to include implicit consideration of acetonitrile solvation effects. ${ }^{14}$ More details of the calculations are given in the Supporting Information. The B3LYP-D3 functional has a reported mean average deviation from $\operatorname{CCSD}(\mathrm{T}) / \mathrm{CSB}$ results of 1.6 and $2.3 \mathrm{kcal} / \mathrm{mol}$ for barrier heights and reaction energies, respectively, in a selection of Pd-catalyzed reactions. ${ }^{13}$ The method has also previously been used to model Heck reactions. ${ }^{16}$

The formation of 3aa, without phosphine ligands, was chosen as a model system for our calculations (Table 1, entry 5 ). Because the experimental reaction was performed with a silver additive in a polar solvent, a fast halide abstraction from palladium was assumed. In other words, all structures were modeled using acetate and acetonitrile ligands.

An extensive screening of migratory insertion transition states and their conformational space was conducted (see SI). Transition state structures (TS1-TS8) for the eight possible arylations are shown in Figure 2. For each possibility, the complexes are depicted in their lowest energy ligand conformations. The lowest energy pathway, TS1 (see SI, Figure S86), leads to $\mathrm{C}-\mathrm{C}$ bond formation in the $\mathrm{C}-4$ position, 


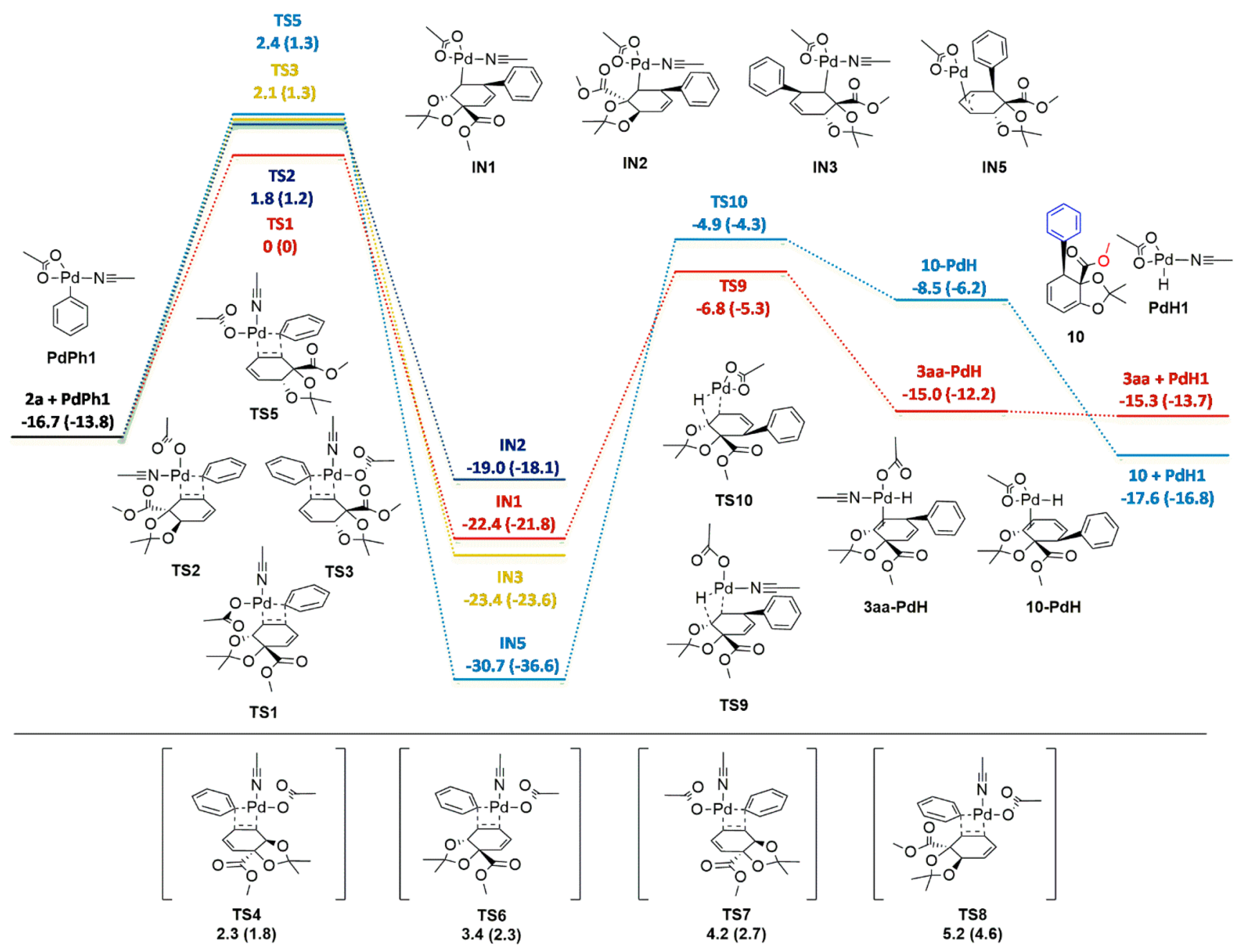

Figure 2. Top: Gibbs energy profile $(1 \mathrm{M}, 298 \mathrm{~K}$, in $\mathrm{kcal} / \mathrm{mol})$ for four of the migratory insertion transition states. Single point energies are calculated at the B3LYP-D3/def2-TZVP and M06/def2-TZVP (within parentheses) levels of theory. Bottom: Structures for higher energy migratory insertion transition states. Energies are shown relative to TS1.

on the face anti to the acetonide moiety. It corresponds well to previously reported Heck-type migratory insertion transition states, with an almost fully formed $\mathrm{Pd}-\mathrm{C}$ bond along with a developing $\mathrm{C}-\mathrm{C}$ bond. ${ }^{17}$ Our calculations predict that TS1 is favored by $1.8 \mathrm{kcal} / \mathrm{mol}$ over the second lowest, TS2 (Figure 2 ). The predominance of TS1 in determining the reaction outcome agrees well with our experimental results, in which 3aa is the only observed Heck product. In addition to TS2, other transition states near in energy to TS1 might contribute under our experimental conditions. These are TS3, predicted to lie $2.1 \mathrm{kcal} / \mathrm{mol}$ higher than TS1, as well as TS4 and TS5, higher by 2.3 and $2.4 \mathrm{kcal} / \mathrm{mol}$, respectively.

The insertion products following TS1, TS2, and TS3 all correspond to structures with palladium bound to an $\mathrm{sp}^{3}$ carbon. These structures, IN1, IN2, and IN3, are all relatively close in energy, with IN2 somewhat less stable, possibly due to steric effects from installing the palladium syn to the acetonide. Insertion product IN5 is different and is significantly more stable compared to IN1-3. The difference can be explained as a result of the formation of a palladium $\pi$-allyl system. The insertion products IN2 and IN3 do not have any available $\beta$ hydrogens, and therefore both lack obvious forward reaction paths toward a Heck-type product (the same holds true for the insertion product following TS4).
One possibility in the absence of $\beta$-hydrogens is a reverse carbopalladation. In a Heck-type reaction, the migratory insertion is generally viewed as irreversible; ${ }^{17 b, c, 18}$ there are however known examples of $\beta$-carbon elimination when no $\beta$ hydrogens are available. ${ }^{19}$ We have estimated the backward reaction barriers for migratory insertion products IN2 and IN3 to $\sim 21 \mathrm{kcal} / \mathrm{mol}$ and $\sim 26 \mathrm{kcal} / \mathrm{mol}$, respectively. These barriers imply that such processes are accessible under the experimental conditions. Therefore, if formed, the formation of IN2 and IN3 should be reversible, and these should be able to proceed to Heck-product 3aa. With a backward reaction barrier of $\sim 33 \mathrm{kcal} / \mathrm{mol}$, the formation of IN5 is irreversible.

In contrast to IN2 and IN3, intermediate IN1 possesses a hydrogen in a syn orientation with respect to the palladium. As expected, a $\beta$-hydride elimination is predicted to follow. The $\beta$ hydride elimination forming product 3 aa was computed to have a barrier of $16 \mathrm{kcal} / \mathrm{mol}$ (TS9). In accordance with the increased stability of the $\pi$-allyl system, the barrier for $\beta$ hydride elimination in IN5 (TS10) was calculated to be 26 $\mathrm{kcal} / \mathrm{mol}$, which should be attainable under the experimental conditions. If formed, IN5 should proceed to form Heckproduct 10 (Figure 2).

Conclusions. We here present a methodology for Pdcatalyzed diastereoselective arylation of dienes derived from 
enzymatic cis-dihydroxylation of benzoic acid. This approach allows for a chirality transfer from the diol moieties of these microbial arene oxidation products to a more distal position, increasing the chiral pool of molecules available by enzymatic dearomatization. The reaction effects coupling of a range of aryl iodides in moderate to excellent yields and selectivity and provides the opportunity to form tricyclic scaffolds via further transformations. A quantum chemical investigation indicates that there is a kinetic preference for arylation in the observed position. Interestingly, it was also found that reversibility in the other accessible carbopalladations might be kinetically relevant for the high selectivity toward the formed Heck product.

\section{ASSOCIATED CONTENT}

\section{Supporting Information}

The Supporting Information is available free of charge at https://pubs.acs.org/doi/10.1021/acs.orglett.0c00708.

Experimental procedures and spectroscopic data, and $\mathrm{X}$ ray data for compound $3 \mathrm{ah}$ (PDF)

Computational chemistry details (Geometries of all calculated structures are available on ioChem-BD; see http://dx.doi.org/10.19061/iochem-bd-6-23) (PDF)

\section{Accession Codes}

CCDC 1961899 contains the supplementary crystallographic data for this paper. These data can be obtained free of charge via www.ccdc.cam.ac.uk/data_request/cif, or by emailing data_request@ccdc.cam.ac.uk, or by contacting The Cambridge Crystallographic Data Centre, 12 Union Road, Cambridge CB2 1EZ, UK; fax: +44 1223336033.

\section{AUTHOR INFORMATION}

\section{Corresponding Authors}

Nina Kann - Department of Chemistry and Chemical Engineering, Chalmers University of Technology, SE-41296 Gothenburg, Sweden; (1) orcid.org/0000-0002-4457-5282; Email: kann@chalmers.se

Simon E. Lewis - Centre for Sustainable Chemical Technologies and Department of Chemistry, Convocation Avenue, University

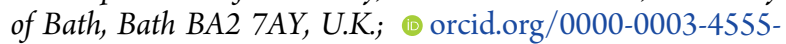
4907; Email: S.E.Lewis@bath.ac.uk

Martin Rahm - Department of Chemistry and Chemical Engineering, Chalmers University of Technology, SE-41296 Gothenburg, Sweden; 이이. orcid.o000-0001-7645-5923; Email: martin.rahm@chalmers.se

\section{Authors}

Andrew J. Paterson - Department of Chemistry and Chemical Engineering, Chalmers University of Technology, SE-41296 Gothenburg, Sweden; (1) orcid.org/0000-0001-7169-2524

Petter Dunås - Department of Chemistry and Chemical Engineering, Chalmers University of Technology, SE-41296 Gothenburg, Sweden; 이이. orcid.org/0000-0002-3779-3265

Per-Ola Norrby - Data Science and Modelling, Pharmaceutical Sciences, R\&D, AstraZeneca Gothenburg, SE-43183 Mölndal, Sweden; orcid.org/0000-0002-2419-0705

Gabriele Kociok-Köhn - Material and Chemical Characterisation Facility, Convocation Avenue, University of Bath, Bath BA2 7AY, U.K.; ○ orcid.org/0000-0002-71861399

Complete contact information is available at: https://pubs.acs.org/10.1021/acs.orglett.0c00708

\section{Author Contributions}

${ }^{\ddagger}$ A.J.P. and P.D. contributed equally.

\section{Notes}

The authors declare no competing financial interest.

\section{ACKNOWLEDGMENTS}

The Swedish Research Council (N.K., Grant 2015-05360), the Swedish Research Council Formas (N.K., Grant 2015-1106), the Engineering and Physical Sciences Research Council (S.E.L., Grant EP/L016354/1), and the Carl Trygger Foundation (A.P., Grant CTS 16:235) are gratefully acknowledged for funding. Computational resources were provided by the Swedish National Infrastructure for Computing (SNIC) at C3SE. We thank Dr. Carl Johan Wallentin, Dept. of Chemistry and Molecular Biology, University of Gothenburg, and Prof. Christer Larsson, Dept. of Biology and Biological Engineering, Chalmers University of Technology, for discussions.

\section{REFERENCES}

(1) Gibson, D. T.; Koch, J. R.; Kallio, R. E. Oxidative Degradation of Aromatic Hydrocarbons by Microorganisms. I. Enzymatic Formation of Catechol from Benzene. Biochemistry 1968, 7, 2653-2662.

(2) Boyd, D. R.; Dorrity, M. R. J.; Hand, M. V.; Malone, J. F.; Sharma, N. D.; Dalton, H.; Gray, D. J.; Sheldrake, G. N. Enantiomeric Excess and Absolute-Configuration Determination of cis-Dihydrodiols from Bacterial Metabolism of Monocyclic Arenes. J. Am. Chem. Soc. 1991, 113, 666-667.

(3) Sun, S. Y.; Zhang, X.; Zhou, Q.; Chen, J. C.; Chen, G. Q. Microbial Production of cis-1,2-Dihydroxy-Cyclohexa-3,5-Diene-1Carboxylate by Genetically Modified Pseudomonas putida. Appl. Microbiol. Biotechnol. 2008, 80, 977-984.

(4) Lewis, S. E., Asymmetric Desymmetrization under Enzymatic Conditions. In Asymmetric Desymmetrization Reactions; You, S.-L., Ed.; Wiley VCH Verlag GmbH \& Co. KGaA.: Weinheim, 2016. DOI: $10.1002 / 9783527698479 . c h 12$.

(5) Reiner, A. M.; Hegeman, G. D. Metabolism of Benzoic Acid by Bacteria - Accumulation of (-)-3,5-Cyclohexadiene-1,2-Diol-1Carboxylic Acid by a Mutant Strain of Alcaligenes eutrophus. Biochemistry 1971, 10, 2530-2536.

(6) (a) Pazos, M.; Gonzalez, B.; Suescun, L.; Seoane, G.; Carrera, I. Production of Enantiopure $\beta$-Amino- $\gamma$-Hydroxyesters from Benzoic Acid by a Selective Formal Aminohydroxylation. Tetrahedron Lett. 2017, 58, 2182-2185. (b) Griffen, J. A.; Kenwright, S. J.; AbouShehada, S.; Wharry, S.; Moody, T. S.; Lewis, S. E. Benzoate Dioxygenase from Ralstonia eutropha B9 - Unusual Regiochemistry of Dihydroxylation Permits Rapid Access to Novel Chirons. Org. Chem. Front. 2014, 1, 79-90. (c) Myers, A. G.; Siegel, D. R.; Buzard, D. J.; Charest, M. G. Synthesis of a Broad Array of Highly Functionalized, Enantiomerically Pure Cyclohexanecarboxylic Acid Derivatives by Microbial Dihydroxylation of Benzoic Acid and Subsequent Oxidative and Rearrangement Reactions. Org. Lett. 2001, 3, 2923-2926.

(7) Ghavre, M.; Froese, J.; Murphy, B.; Simionescu, R.; Hudlicky, T. A Formal Approach to Xylosmin and Flacourtosides $\mathrm{E}$ and $\mathrm{F}$ : Chemoenzymatic Total Synthesis of the Hydroxylated Cyclohexenone Carboxylic Acid Moiety of Xylosmin. Org. Lett. 2017, 19, $1156-1159$.

(8) (a) Charest, M. G.; Lerner, C. D.; Brubaker, J. D.; Siegel, D. R.; Myers, A. G. A Convergent Enantioselective Route to Structurally Diverse 6-Deoxytetracycline Antibiotics. Science 2005, 308, 395-398. (b) Ali Khan, M.; Mahon, M. F.; Lowe, J. P.; Stewart, A. J. W.; Lewis, S. E. Valuable New Cyclohexadiene Building Blocks from Cationic $\eta^{5}$ Iron-Carbonyl Complexes Derived from a Microbial Arene Oxidation Product. Chem. - Eur. J. 2012, 18, 13480-13493. 
(9) de Meijere, A.; Bräse, S.; Oestreich, M. Metal-Catalyzed CrossCoupling Reactions and More; Wiley-VCH Verlag GmbH \& Co. KGaA: Weinheim, 2014. DOI: 10.1002/9783527655588.

(10) (a) Mizoroki, T.; Mori, K.; Ozaki, A. Arylation of Olefin with Aryl Iodide Catalyzed by Palladium. Bull. Chem. Soc. Jpn. 1971, 44, 581-581. (b) Heck, R. F.; Nolley, J. P. Palladium-Catalyzed Vinylic Hydrogen Substitution Reactions with Aryl, Benzyl, and Styryl Halides. J. Org. Chem. 1972, 37, 2320-2322. (c) Roy, D.; Uozumi, Y. Recent Advances in Palladium-Catalyzed Cross-Coupling Reactions at ppm to ppb Molar Catalyst Loadings. Adv. Synth. Catal. 2018, 360, 602-625.

(11) (a) Arai, I.; Lee, T. D.; Hanna, R.; Daves, G. D. PalladiumCatalyzed Reactions of Glycals with (1,3-Dimethyl-2,4(1H,3H)pyrimidinedion-5-yl)Mercuric Acetate. Facile Regio- and Stereospecific C-Nucleoside Syntheses. Organometallics 1982, 1, 742-747.

(b) Daves, G. D. C-Glycoside Synthesis by Palladium-Mediated Glycal Aglycon Coupling Reactions. Acc. Chem. Res. 1990, 23, 201206. (c) Lei, M.; Gao, L.; Yang, J. S. Microwave-Assisted PalladiumCatalyzed Cross-Coupling Reactions between Pyranoid Glycals and Aryl Bromides. Synthesis of 2'-Deoxy C-Aryl- $\beta$-Glycopyranosides. Tetrahedron Lett. 2009, 50, 5135-5138. (d) Mabit, T.; Siard, A.; Legros, F.; Guillarme, S.; Martel, A.; Lebreton, J.; Carreaux, F.; Dujardin, G.; Collet, S. Stereospecific C-Glycosylation by MizorokiHeck Reaction: A Powerful and Easy-to-Set-up Synthetic Tool to Access $\alpha$ - and $\beta$-Aryl-C-Glycosides. Chem. - Eur. J. 2018, 24, 1406914074.

(12) (a) Matveenko, M.; Kokas, O. J.; Banwell, M. G.; Willis, A. C. Chemoenzymatic Approaches to Lycorine-Type Amaryllidaceae Alkaloids: Total Syntheses of ent-Lycoricidine, 3-epi-ent-Lycoricidine, and 4-Deoxy-3-epi-ent-Lycoricidine. Org. Lett. 2007, 9, 3683-3685. (b) Griffen, J. A.; Le Coz, A. M.; Kociok-Kohn, G.; Khan, M. A.; Stewart, A. J. W.; Lewis, S. E. Expanding the Chiral Pool: Oxidation of meta-Bromobenzoic Acid by $R$. eutrophus B9 Allows Access to New Reaction Manifolds. Org. Biomol. Chem. 2011, 9, 3920-3928. (c) Dlugosch, M.; Ma, X. H.; Yang, S. X.; Banwell, M. G.; Ma, C. X.; Ward, J. S.; Carr, P. Syntheses of Structurally and Stereochemically Varied Forms of $\mathrm{C}_{7} \mathrm{~N}$ Aminocyclitol Derivatives from Enzymatically Derived and Homochiral cis-1,2-Dihydrocatechols. Org. Lett. 2018, $20,7225-7228$ and references cited therein.

(13) Frisch, M. J.; Trucks, G. W.; Schlegel, H. B.; Scuseria, G. E.; Robb, M. A.; Cheeseman, J. R.; Scalmani, G.; Barone, V.; Petersson, G. A.; Nakatsuji, H.; Li, X.; Caricato, M.; Marenich, A. V.; Bloino, J.; Janesko, B. G.; Gomperts, R.; Mennucci, B.; Hratchian, H. P.; Ortiz, J. V.; Izmaylov, A. F.; Sonnenberg, J. L.; Williams; Ding, F.; Lipparini, F.; Egidi, F.; Goings, J.; Peng, B.; Petrone, A.; Henderson, T.; Ranasinghe, D.; Zakrzewski, V. G.; Gao, J.; Rega, N.; Zheng, G.; Liang, W.; Hada, M.; Ehara, M.; Toyota, K.; Fukuda, R.; Hasegawa, J.; Ishida, M.; Nakajima, T.; Honda, Y.; Kitao, O.; Nakai, H.; Vreven, T.; Throssell, K.; Montgomery, J. A., Jr.; Peralta, J. E.; Ogliaro, F.; Bearpark, M. J.; Heyd, J. J.; Brothers, E. N.; Kudin, K. N.; Staroverov, V. N.; Keith, T. A.; Kobayashi, R.; Normand, J.; Raghavachari, K.; Rendell, A. P.; Burant, J. C.; Iyengar, S. S.; Tomasi, J.; Cossi, M.; Millam, J. M.; Klene, M.; Adamo, C.; Cammi, R.; Ochterski, J. W.; Martin, R. L.; Morokuma, K.; Farkas, O.; Foresman, J. B.; Fox, D. J. Gaussian 16, Rev. C.01; Gaussian Inc.: Wallingford, CT, 2016.

(14) Marenich, A. V.; Cramer, C. J.; Truhlar, D. G. Universal Solvation Model Based on Solute Electron Density and on a Continuum Model of the Solvent Defined by the Bulk Dielectric Constant and Atomic Surface Tensions. J. Phys. Chem. B 2009, 113, 6378-6396.

(15) Steinmetz, M.; Grimme, S. Benchmark Study of the Performance of Density Functional Theory for Bond Activations with (Ni,Pd)-Based Transition-Metal Catalysts. ChemistryOpen 2013, $2,115-124$

(16) (a) Ahlquist, M. S. G.; Norrby, P.-O. Dispersion and BackDonation Gives Tetracoordinate $\left[\mathrm{Pd}\left(\mathrm{PPh}_{3}\right)_{4}\right]$. Angew. Chem., Int. Ed. 2011, 50, 11794-11797. (b) Menezes da Silva, V. H.; de Lima Batista, A. P.; Navarro, O.; Braga, A. A. C. Theoretical Study on Selectivity Trends in ( $N$-Heterocyclic Carbene)-Pd Catalyzed
Mizoroki-Heck Reactions: Exploring Density Functionals Methods and Molecular Models. J. Comput. Chem. 2017, 38, 2371-2377. (c) Reddi, Y.; Tsai, C.-C.; Avila, C. M.; Toste, F. D.; Sunoj, R. B. Harnessing Noncovalent Interactions in Dual-Catalytic Enantioselective Heck-Matsuda Arylation. J. Am. Chem. Soc. 2019, 141, 9981009.

(17) (a) Albert, K.; Gisdakis, P.; Rösch, N. On C-C Coupling by Carbene-Stabilized Palladium Catalysts: A Density Functional Study of the Heck Reaction. Organometallics 1998, 17, 1608-1616. (b) Beletskaya, I. P.; Cheprakov, A. V. The Heck Reaction as a Sharpening Stone of Palladium Catalysis. Chem. Rev. 2000, 100, 3009-3066. (c) Bäcktorp, C.; Norrby, P. O. Trans Effects in the Heck Reaction - A Model Study. J. Mol. Catal. A: Chem. 2010, 328, 108-113.

(18) Dang, Y. F.; Qu, S. L.; Wang, Z. X.; Wang, X. T. A Computational Mechanistic Study of an Unprecedented Heck-Type Relay Reaction: Insight into the Origins of Regio- and Enantioselectivities. J. Am. Chem. Soc. 2014, 136, 986-998.

(19) (a) Catellani, M.; Frignani, F.; Rangoni, A. A Complex Catalytic Cycle Leading to a Regioselective Synthesis of o,o'Disubstituted Vinylarenes. Angew. Chem., Int. Ed. Engl. 1997, 36, 119-122. (b) Campora, J.; Gutierrez-Puebla, E.; Lopez, J. A.; Monge, A.; Palma, P.; del Rio, D.; Carmona, E. Cleavage of the C-Alkyl-C-Aryl Bond of Pd- $\mathrm{CH}_{2} \mathrm{CMe}_{2} \mathrm{Ph}$ Complexes. Angew. Chem., Int. Ed. 2001, 40, $3641-3644$. 